\title{
DIVISÃO SEXUAL DO TRABALHO NO BRASIL: MULHER CUIDADORA E HOMEM PROVEDOR?
}

\section{Sexual division of labor in brazil: male breadwinner and female caregiver?}

\author{
Marcio Rogério Kurz ${ }^{22}$ \\ Nanci Stancki da $\mathrm{Luz}^{23}$
}

\section{Resumo}

Um aspecto marcante do mundo do trabalho é o acentuado crescimento da participação feminina, aumento acompanhado pela ampliação do número de domicílios che ados por mulheres e da sua contribuição para a renda familiar, alterando, de alguma forma, a tradicional divisão sexual do trabalho, que atribui à mulher a função de cuidadora e ao homem a função de provedor do lar. A redução do número de Ihos, o aumento das famílias sem Ihos e de famílias monoparentais são alterações que in uenciaram em outras formas de arranjos familiares. Este estudo quantitativo, apoiado na estatística descritiva, buscou conhecer e comparar diversos aspectos nas relações e realidades das mulheres no mundo do trabalho, sob a ótica da divisão sexual do trabalho, em um período de 10 anos no Brasil. Os dados são da Pesquisa Nacional por Amostra de Domicílios (PNAD) do Instituto Brasileiro de Geogra a e Estatística (IBGE) para os anos de 2002 e 2011.

Palavras-chave: Mundo do Trabalho. Mulher Cuidadora. Homem Provedor. Divisão Sexual do Trabalho. Relações de Gênero.

\section{Abstract}

A striking aspect of the world of work is the sharp increase in female participation, increase followed by the rise in the number of households headed by women and their contribution to the family income, changing somehow the traditional sexual division of labor that assigns to women the role of caregiver and to man the role of provider of home. Reducing the number 
of children, the increase in households without children and single parent families are in uencing changes in other forms of family arrangements. This quantitative study, supported by the descriptive statistics, sought to know and compare different aspects in relationships and realities of women in the workplace, from the perspective of the sexual division of labor in a period of 10 years in Brazil. Data are from the National Household Sample Survey (PNAD) of the Brazilian Institute of Geography and Statistics (IBGE) for the years 2002 and 2011.

Keywords: World of Work. Woman Caregiver. Man Provider. Sexual Division of Labor. Gender Relations.

\section{Introdução}

Em 1872, quando foi realizado o primeiro recenseamento no Brasil, a população era de 9.930 .478 habitantes. Durante 139 anos a população cresceu quase 20 vezes, segundo apontam os resultados da Pesquisa Nacional por Amostra de Domicílios (PNAD), do Instituto Brasileiro de Geogra a e Estatística (IBGE). Em 2011, a marca chegou a 195.243.000 habitantes, dos quais 100.504 .000 eram de mulheres, perfazendo $51,48 \%$ do total da população. (PNAD, 2011, p. 44).

Considerando este quantitativo da população feminina brasileira, analisam-se as demandas das mulheres, dentre as quais a busca de condições justas e igualitárias no mundo do trabalho feminino.

Desta forma, este artigo pretende contribuir com o debate e os estudos sobre a participação das mulheres no mercado de trabalho brasileiro entre os anos de 2002 e 2011, analisando alguns indicadores desta população, na perspectiva dos estudos da divisão sexual do trabalho. As informações a serem analisadas serão baseadas nos dados da Pesquisa Nacional por Amostra de Domicílios (PNAD), do Instituto Brasileiro de Geogra a e Estatística (IBGE), para os anos de 2002 e 2011, perfazendo, portanto, dez anos de análise.

\section{Divisão sexual do trabalho}

Ao longo da história da humanidade o trabalho foi diferenciado entre homens e mulheres, seja em termos de suas características, seja pelo seu 
reconhecimento ou sua remuneração. O conceito de gênero se coloca como fundamental para a compreensão destas diferenciações. As formas de inserção e permanência no mercado de trabalho variam segundo o gênero - não pelas diferenças siológicas e de natureza - mas pelas relações culturais, sociais e econômicas que designam diferentes condições de acesso ao mercado de trabalho tanto para os homens quanto para as mulheres. (OIT/ MTE, 2002, p. 23).

A divisão sexual do trabalho é modulada histórica e socialmente, designando os homens, prioritariamente, como provedores da família, responsáveis pela esfera produtiva - espaço público (masculino) - e protagonistas de atividades com maior valor social adicionado. As mulheres, entretanto, como cuidadoras da família, foram designadas para a esfera reprodutiva - espaço privado (feminino) - exercendo papéis com menor valor social adicionado. (HIRATA; KERGOAT, 2007, p. 599).

A pesquisadora Silvia Yannoulas (2002, p. 15) conceituou a divisão sexual do trabalho da seguinte forma:

\begin{abstract}
Divisão sexual do trabalho: é uma categoria utilizada pelas Ciências Sociais para indicar que, em todas as sociedades, homens e mulheres realizam tarefas distintas. Entretanto, as tarefas atribuídas a cada sexo variam de cultura para cultura, ou ainda dentro da mesma cultura, de uma época para outra. Ressaltamos a questão temporal porque é uma característica fundamental das relações de gênero: sua mutabilidade no tempo. Por exemplo: a docência era uma tarefa fundamentalmente masculina nos inícios da pro ssão, na Europa. Quando nos defrontamos com estas mudanças temporais no exercício de uma pro ssão, é importante observar quais foram os fundamentos que deram origem a tal mudança, pois exprimem novas formulações culturais das relações entre os gêneros. (YANNOULAS, 2002, p. 15, grifo da autora).
\end{abstract}

Outro aspecto da divisão sexual do trabalho é a conciliação entre as atividades da vida familiar e as atividades da vida pro ssional. Helena Hirata (2010, p. 2) descreveu quatro modelos de conciliação para as atividades da vida familiar:

\title{
Modelo tradicional:
}

Considera que a mulher não trabalha no mercado formal, apenas exercendo o papel de cuidar dos afazeres domésticos e dos lhos. Ao homem é reservado o papel de provedor do lar. 
Modelo da conciliação:

A mulher trabalha em atividade formal e exerce as responsabilidades do trabalho pro ssional (público), conciliando-as, somente ela, com as atividades do lar (privado). Já o homem não concilia.

Modelo da parceria:

As mulheres e os homens são parceiros e suas relações são de igualdade e não de poder. As atividades domésticas e os cuidados da família são exercidos e repartidos por ambos, resultando em igualdade entre os sexos.

Modelo da delegação:

Este modelo traz uma "solução" para o antagonismo entre as atividades pro ssionais e os afazeres domésticos. A mulher delega a outra mulher as atividades domésticas e os cuidados da família.

A crescente participação das mulheres, tanto no mercado formal de trabalho quanto nas atividades informais, é acompanhada pelo crescimento do emprego vulnerável, precário e exível. De um lado existem mulheres estabilizadas pro ssionalmente, atuando em atividades intelectualizadas, com melhores condições e remunerações, e, de outro, mulheres que se mantêm em ocupações consideradas pouco quali cadas, com baixa remuneração e precarizadas. Esta bipolarização do trabalho feminino traz antagonismos e desigualdades, tanto entre mulheres e homens, quanto entre as próprias mulheres. (HIRATA, 2011, p. 14; 2010, p. 1).

A Tabela 1 apresenta os dados quantitativos sobre a participação de homens e mulheres no mercado de trabalho, os quais foram coletados pelo IBGE na Pesquisa Nacional por Amostra de Domicílios (PNAD) com amostragem em todo o território brasileiro nos anos de 2002 a 2011.

A Tabela 1 apresenta os dados das pessoas com 10 anos ou mais e que estavam trabalhando na semana da pesquisa. Os dados são comparados entre os anos de 2002 e 2011. Observa-se que, do total de aproximadamente 100 milhões de pessoas trabalhadoras brasileiras, as mulheres registraram um crescimento de $17,68 \%$ na participação no mercado de trabalho em 2011, quando comparado a 2002. São 6,5 milhões de mulheres a mais no mercado de trabalho em 10 anos. Já os homens registraram um crescimento menor, de $13,75 \%$ para o mesmo período. 
Tabela 1 - Pessoas de 10 anos ou mais de idade, economicamente ativas

na semana de referência, por sexo - Brasil (Mil pessoas)

\begin{tabular}{c|c|c|c}
\hline Sexo & 2002 & 2011 & 100.223 \\
\hline Total & 86.835 & 56.850 & 15,42 \\
\hline Homem & 49.979 & 43.373 & 17,68 \\
\hline
\end{tabular}

Fonte: IBGE - PNAD. Elaboração própria.

Este signi cativo crescimento das mulheres no mercado de trabalho brasileiro guarda uma estreita relação com o número de mulheres que são responsáveis pelo domicílio. Em 2002 eram 1.704.000 mulheres responsáveis pelo lar, e, em 2011, este quantitativo chegou a 7.671.000, um aumento expressivo de $350 \%$, enquanto o aumento do número de homens responsáveis pelo domicílio foi de apenas $2,97 \%$, conforme demonstrado na Tabela 2.

Tabela 2 - Pessoas residentes em domicílios particulares e sexo da pessoa de referência, por sexo - Brasil (Mil pessoas)

\begin{tabular}{c|c|c|c|}
\hline Sexo & 2002 & 2011 & 41.721 \\
\hline Total & 34.771 & 34.050 & 19,99 \\
\hline Homem & 33.067 & 7.671 & 350,18 \\
\hline
\end{tabular}

Fonte: IBGE - PNAD. Elaboração própria.

Por outro lado, observa-se, também, que o número de homens responsáveis pelo domicílio ainda é muito maior que o de mulheres: são 34.050 .000 contra 7.671.000 em 2011, perfazendo uma diferença de 343,88\%.

Outra mudança signi cativa que se observa na sociedade com maior participação das mulheres trabalhadoras é o número de casais com Ihos e sem Ihos. Em 2002 eram 5.572.997 casais que tinham Ihos em idades variadas, e em 2011 esse quantitativo passou a ser de 5.412.934, uma redução de $2,96 \%$, mesmo com o crescimento geral da população, conforme apresentado na Tabela 3. 
Tabela 3 - Casal com Ihos de idades variadas - Brasil

\begin{tabular}{l|c|c|c}
\hline Tipo & 2002 & 2011 & $\%$ \\
\hline Casal com Ihos & 5.572 .997 & 5.412 .934 & $-2,96$ \\
\hline
\end{tabular}

Fonte: IBGE - PNAD. Elaboração própria.

Já no número de casais sem Ihos ocorreu um aumento expressivo em 2002 eram 7.321 .177 e em 2011 registraram-se 11.923.067 casais sem Ihos, importando em crescimento da ordem de $62,86 \%$, conforme demonstrado na Tabela 4.

Tabela 4 - Casal sem Ihos - Brasil

\begin{tabular}{c|c|c}
\hline Tipo & 2002 & 2011 \\
\hline Casal sem lhos & 7.321 .177 & 11.923 .067 \\
\hline
\end{tabular}

Fonte: IBGE - PNAD. Elaboração própria.

Esta transformação é explicada, em parte, pelas transformações tecnológicas ocorridas na biologia e medicina, que possibilitaram maior controle sobre a gravidez e a reprodução humana. (CASTELLS, 1999, p. 171).

Outro aspecto relacionado às mudanças ocorridas na sociedade em função da maior participação das mulheres no mercado de trabalho, é o número de residências em que há apenas um morador. Em 2002 existiam 5.017.199 de domicílios com um morador. Destes, 2.512.714 eram de domicílios com apenas uma mulher moradora. Já em 2011 o número total de moradores solitários passou a ser de 7.853.935, dos quais 4.036.038 eram de mulheres morando sozinhas, ou seja, um crescimento da ordem de $60,62 \%$.

A Tabela 5 mostra o número de pessoas com 10 anos ou mais de idade e seus rendimentos agrupados por classes de rendimento mensal. Observa-se que houve uma redução signi cativa de homens e mulheres que deixaram de ganhar mais de 10 salários mínimos em um período de 10 anos. Houve uma redução de aproximadamente $30 \%$ no grupo de indivíduos com maior remuneração na sociedade brasileira. 
Tabela 5 - Pessoas de 10 anos ou mais de idade e valor do rendimento médio mensal,

por sexo - Brasil (Mil pessoas)

\begin{tabular}{|c|c|c|c|c|}
\hline Sexo & Classe de Rendimento Mensal & 2002 & 2011 & $\%$ \\
\hline \multirow[t]{5}{*}{ Homem } & Total & 67.525 & 77.866 & 15,31 \\
\hline & Até 3 salários mínimos & 34.497 & 45.214 & 31,07 \\
\hline & Mais de 3 a 10 salários mínimos & 11.197 & 10.722 & $-4,24$ \\
\hline & Mais de 10 salários mínimos & 3.155 & 2.171 & $-31,19$ \\
\hline & Sem rendimento & 18.676 & 19.759 & 5,80 \\
\hline \multirow[t]{5}{*}{ Mulher } & Total & 72.914 & 84.865 & 16,39 \\
\hline & Até 3 salários mínimos & 32.334 & 46.817 & 44,79 \\
\hline & Mais de 3 a 10 salários mínimos & 6.003 & 6.009 & 0,10 \\
\hline & Mais de 10 salários mínimos & 1.361 & 948 & $-30,35$ \\
\hline & Sem rendimento & 33.216 & 31.091 & $-6,40$ \\
\hline
\end{tabular}

Fonte: IBGE - PNAD. Elaboração própria.

Em relação aos rendimentos médios mensais observa-se que tanto homens quanto mulheres estão, em sua maioria, na classe de trabalhadores que ganham até 3 salários mínimos mensais - são 45.214 .000 homens, um crescimento de $31,07 \%$ em 10 anos, e 46.817 .000 mulheres, registrando um crescimento expressivo de $44,79 \%$ em 10 anos. Ainda nesta classe de renda estão 92.031 .000 de pessoas trabalhadoras, o que representa $82,26 \%$ da população brasileira, que, em 2011, obteve algum rendimento médio mensal de até 3 salários mínimos mensais. 
Em estudo próprio, Castells (1999, p. 200) pontuou que "as mulheres ocupam cargos que exigem quali cações semelhantes em troca de salários menores, com menos segurança no emprego e menores chances de chegar às posições mais elevadas".

Observa-se, ainda, na Tabela 5, que o número de mulheres sem rendimento registrou uma redução de $6,40 \%$, enquanto o número de homens sem rendimento aumentou em $5,80 \%$, isto é, eram 18.676 .000 em 2002, passando a 19.759 .000 em 2011. Estes números representam um aumento de 1.083 .000 homens sem renda em um período de 10 anos, ou seja, 108.300 homens que caram sem renda por ano, ou ainda, aproximadamente, 300 homens por dia.

\section{Considerações nais}

É inquestionável que as famílias e o mercado de trabalho passaram por profundas transformações com a inserção das mulheres no mundo do trabaIho remunerado. Para este grande contingente de mulheres trabalhadoras ainda existe a dupla e até a tripla jornada de trabalho, que no âmbito particular Ihes impõe o cuidar dos Ihos, do marido e das tarefas femininas típicas do sistema patriarcal. E, no âmbito público, lhes impõe enormes diferenças salariais e atividades precarizadas em relação aos homens.

Este estudo apresentou uma série de indicadores, como por exemplo, o crescimento das mulheres no mercado de trabalho brasileiro. Foram 6.500.000 mulheres a mais no mercado de trabalho em apenas 10 anos, registrando um crescimento de $17,68 \%$.

Este crescimento das mulheres no mercado de trabalho contribui para diversas transformações da sociedade, dentre as quais novos arranjos familiares e alterações na divisão sexual do trabalho. Este estudo apresentou o quantitativo de 7.671.000 mulheres responsáveis pelo lar em 2011, um aumento expressivo de $350 \%$. Estas mulheres, com renda própria, passaram a ter maior poder de negociação nas divisões das tarefas do lar, por exemplo.

Outra alteração que se observa é a redução de $2,96 \%$ no número de famílias com Ihos em idades variadas e o crescimento de $62,86 \%$ no número de casais sem Ihos - foram registrados 11.923 .067 casais nesta situação em 2011.

A inserção da mulher no mercado de trabalho possibilitou maior auto- 
nomia feminina, o que colaborou para a ampliação do número de mulheres que moram sozinhas, uma vez que as pesquisas indicaram 4.036.038 muIheres morando nesta condição em 2011, apontando um crescimento de $60,62 \%$ em 10 anos. Outro indicador importante nestas transformações da sociedade foi o número de mulheres sem rendimento, que registrou uma redução de 6,40\% em 2011 .

Diante disso, observa-se que se amplia o número de mulheres com possibilidade de autonomia nanceira, o que contribui para as mudanças nas relações de gênero, permitindo também alterações na divisão sexual do trabalho e no enfraquecimento da percepção de mulher apenas como cuidadora e do homem como único provedor.

\section{Referências}

CASTELLS, Manuel. O m do patriarcalismo: movimentos sociais, família e sexualidade na era da informação. In: O Poder da identidade. Tradução: Klauss Brandini Gerhardt. São Paulo. Paz e Terra, 1999, p. 169-278.

HIRATA, Helena; KERGOAT, Danièle. Novas con gurações da divisão sexual do trabalho. Cadernos de Pesquisa, São Paulo, v. 37, n. 132, p. 595-609, set./dez. 2007.

HIRATA, Helena. Novas con gurações da divisão sexual do trabalho. Revista Tecnologia e Sociedade, Curitiba, n. 11, $2^{\circ}$ Semestre de 2010.

HIRATA, Helena. Tendências recentes da precarização social e do trabalho: Brasil, França, Japão. In: DRUCK, Graça \& FRANCO, Tânia (org.). TrabaIho, precarização e resistências. Caderno $\mathrm{CRH}$, Salvador, n. 01, v. 24, p.13-20, 2011.

IBGE - INSTITUTO BRASILEIRO DE GEOGRAFIA E ESTATÍSTICA. Pesquisa nacional por amostra de domicílios - 2002 e 2011. Rio de Janeiro: IBGE, 2011. Disponível em: <http://www.ibge.com.br/home/estatistica/populacao/trabalhoerendimento/pnad2011/default.shtm>. Acesso em: jun. 2013.

OIT/MTE. Referencial de Planejamento - Diversidade e Educação Pro ssional. 1 ed. - Brasília: OIT, 2002. 56 p.

YANNOULAS, Silvia C. Dossiê: políticas públicas e relações de gênero no mercado de trabalho. Brasília: CFEMEA; FIG/CIDA, 2002. 